\title{
Effects of unenhanced, enhanced, and elaborated input on learning English phrasal verbs
}

Birjandi, Parviz

Islamic Azad University, Science and Research Branch, Tehran, Iran (pbirjandi@yahoo.com)

Alavi, Seyed Mohammed

University of Tehran, Iran (smalavi@ut.ac.ir)

Najafi Karimi, Shaban $\measuredangle$

Islamic Azad University, Science and Research Branch, Tehran, Iran (najafibox@yahoo.com)

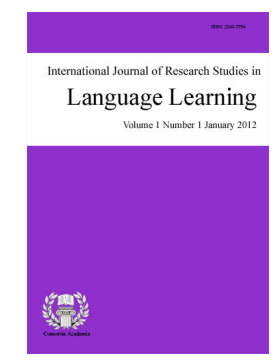

ISSN: 2243-7754 Online ISSN: 2243-7762

OPEN ACCESS

\section{Abstract}

It has been suggested that phrasal verbs create special problems for language learners because of their diversity both in terms of number and in terms of form (Cornell, 1985; Side, 1990). It has been a source of argument for researchers to determine what type of input is more effective in teaching and learning English vocabulary, including phrasal verbs. This study has been conducted to examine the relative effectiveness of three types of input - unenhanced input, typographically enhanced input and lexically elaborated input - on learning English phrasal verbs. To do so, a time series quasi-experimental study was carried out, in which six different texts in three different forms - unenhanced, enhanced and elaborated - were given to 35 Iranian intermediate EFL learners to read. After the participants read each version of the input, a post-test including the target phrasal verbs practiced in each section of the treatment was delivered to answer. Results of related samples Friedman's two-way ANOVA on the pre-tests and post-tests showed that the participants' scores on the post-tests were higher after reading the elaborated texts than their scores after reading the unenhanced and enhanced texts. It has been concluded that (a) typographical input enhancement better helps L2 learners learn English phrasal verbs as compared with unenhanced input, (b) lexical input elaboration better facilitates the learning of English phrasal verbs by L2 learners as compared with unenhanced input, and (c) lexical input elaboration is more effective than input enhancement in helping L2 learners to learn English phrasal verbs.

Keywords: input elaboration; input enhancement; input modification; phrasal verbs; unenhanced input 


\section{Effects of unenhanced, enhanced, and elaborated input on learning English phrasal verbs}

\section{Introduction}

Developing vocabulary is an important part of any effort to learn a second or foreign language without which it would be rather impossible either to decode the message expressed by others or to encode one's own thoughts and ideas into language. Considering the large repertoire of words in a language and the limited exposure of L2 learners in foreign language learning context, one can argue that vocabulary learning is a demanding task for language learners. And when it comes to phrasal verbs, it can get even more difficult. It has been suggested that phrasal verbs create special problems for language learners because of their diversity both in terms of number and in terms of forms (Cornell, 1985; Side, 1990). Consequently, language learners and teachers have always been interested in finding the most influential ways to learn and teach phrasal verbs so much so that various types of techniques and strategies have been examined as to find the most effective way to teach them. Accordingly, two lines of research have encouraged the present study.

One line of research motivating the present study comes from research projects that have studied the role of implicit and explicit interventions in teaching and learning phrasal verbs (Hare, 2010; Khatib \& Ghannadi, 2011). It is a generally agreed upon fact that input plays a crucial role in shaping learners' acquisition of an L2. Current research in Second Language Acquisition (SLA) is interested to obtain a precise understanding of how learners process, or interact with, input to develop their knowledge of the second language. Considering the proposition that not all of the input that learners are exposed to is utilized as intake for learning, recent research in cognitive psychology and SLA has examined the role of attention as a mediating factor between input and learning. Findings of such research suggest that attention is necessary for learning to take place (Robinson, 1995; Schmidt, 1990, 2001).

Another group of research work that has encouraged the present study is related to studies that have considered the role of input enhancement on teaching vocabulary ( Keating, 2008; Kim, 2008) and phrasal verbs (Sjoholm, 1995). In fact, visual input enhancement, which is an implicit means of drawing the learners' attention to form contained in the written input (Doughty \& Williams, 1998), has been extensively-used to direct learners' attention to the incoming input.

In general, there are two methods of input enhancement i.e. (1) typographical (written input) enhancement and (2) intonational (oral input) enhancement. It is believed that input enhancement has the potentials to increase the chances that learners will notice and pay attention to certain target language features, though they may not necessarily turn into intake for further processing. The basic method of enhancement is simply increasing the perceptual salience of the target form through combinations of various techniques (e.g., bolding, capitalizing, or underlining), sometimes followed by an explicit mention to the learners to attend to the highlighted form (Izumi, 2000).

A number of studies have explored the theory of input enhancement (Combs, 2009; Doughty, 2001; VanPatten, 1990) or investigated the role of input enhancement on different areas of language, especially, grammar (Lee \& Huang, 2008; Kuiken \& Vedder, 2002; Rott, 2007; Wong, 2012), structure ( Abadikhah \& Shahriyarpour, 2012), writing (Storch, 1998, Van Gelderen, Snellings , \& De Glopper, 2004), reading (Lee, 2007), and vocabulary ( Izumi, 2002; Kim, 2008; Maftoon \& Sharifi Haratmeh, 2012; Rassaei, \& Karbor, 2013). The role of input elaboration, however, has rarely been dealt with in promoting learners' knowledge of English (Kim, 2003), in general, and in teaching and learning English phrasal verbs, in particular. Even though the importance of phrasal verbs as a subcategory of vocabulary has been recognized and many authors have asserted that they create special problems for L2 learners, there has been little research so far on testing the factors or 
Effects of unenhanced, enhanced, and elaborated input on learning English phrasal verbs

conditions that influence learning and teaching phrasal verbs (Liu, 2003; Nassaji \& Tian, 2010).

The significance of the present study lies in the fact that it focuses on the investigation of a rarely explored subcategory of English vocabulary i.e. phrasal verbs. Phrasal verbs and other idiomatic expressions have been the focus of some recent research projects. But whether the use of enhanced input and elaborative modifications would lead to better noticing and learning of phrasal verbs has not been properly dealt with in previous studies, hence the motive for the present study.

\section{Background}

\subsection{Input enhancement}

It has been argued that drawing L2 learners' attention to certain target language forms helps learners to "notice the gap", as used by Swain (1993), between their current knowledge of L2 and the target language. As suggested by Schmidt's (1994) Noticing Hypothesis, noticing L2 features in the written or spoken input to which L2 learners are exposed is "the necessary and sufficient condition for the conversion of input into intake for learning to take place” (p. 17). Various techniques have been designed that are used to draw learners' attention to formal features in L2 input. These techniques have been called "conscious raising" (Sharwood Smith, 1981) or "input enhancement" (Sharwood Smith, 1993) in SLA literature. Visual input enhancement has been defined as an implicit method of drawing the learners' attention to particular forms of the incoming written input (Doughty \& Williams, 1998). The most common way of input enhancement is simply increasing what has been termed as "the perceptual salience" of the target form through different techniques of modifying the format of a text (e.g., bolding, capitalizing, or underlining), sometimes followed by an explicit mention to the learners to attend to the enhanced forms (Izumi, 2000).

Sharwood-Smith (1993) introduced the concept of input enhancement for the first time with reference to role of grammar in L2 instruction, but later the targets of enhancement have been extended to other linguistic forms including lexical items. One important technique of input enhancement is "textual enhancement". Textual enhancement is known by using one or more typographical cues (e.g., boldfacing, italicizing, underlining, coloring, enlarging the font size, changing the font type) to draw learners' attention to particular forms in a text (Wong, 2005). The purpose of textual enhancement is to make certain forms of the incoming input more noticeable to the learners; forms that may otherwise go unnoticed by learners. This increased salience to input is said to improve form-meaning connections for the target language. Moreover, textual enhancement is believed to have the potentials to direct learners' attention to the target forms while encouraging them to process target language features for meaning.

A number of studies have been undertaken to investigate whether textual enhancement is effective in drawing L2 learners' attention to the target forms (Alanen, 1995; Cho, 2010; Shook, 1994; Williams, 1999), and the results were different. Most of the previous studies on input enhancement have been of the first type (i.e., typographical textual enhancement) (e.g., Alanen, 1995; Doughty, 1991; Izumi, 2002; Jourdenais, 1998; Jourdenais, ota, Stauffer, Boyson, \& Doughty, 1995; Leeman, Arteagotia, fridman, \& Doughty, 1995; Leow, 1997; Overstreet, 1998; Shook, 1994; White, 1998; Wong, 2003). In these studies input enhancement has been achieved by either manipulating a text typographically (e.g., larger font size or different font types) or employing typographical effects(e.g., bold face, italics, capital letters, underlining, coloring), or a combination of the two techniques in the same text (Jourdenais, Ota, Stauffer, Boyson, \& Doughty, 1995).

The effectiveness of typographical input enhancement has been tested in a number of studies, some of which have provided mixed results. One group of studies reported that this type of enhancement not only leads to more noticing of the enhanced forms, but it also facilitates learning of those language features. For example, Shook (1994) studied visual or textual enhancement in second language context to determine whether this kind of input was effective in drawing learners' attention to L2 forms. The participants in this study were divided into three 
groups. In the first group, the subjects received enhanced passages (a larger character size and bold type for the target forms), with an explicit mention to pay attention to the enhanced forms. The second group received the same enhanced versions of the texts, but without any explicit mention to pay attention to the enhanced target features. The participants in the third group (the control group) received the same materials without typographical modifications, and they also were not explicitly told to pay attention to anything in particular.

Findings from this study show that the subjects in the first two groups, who received the enhanced versions of the passages, performed significantly better than the third group, who read the unenhanced versions of all the texts. Shook (1994) subsequently states that textual enhancement made a difference, and gave the participants the ability to recognize and produce the target forms. He also points out that there were no significant differences between the first group (who were told explicitly to pay attention to the enhanced forms) and those who did not receive this explicit instruction. This means that reading the enhanced versions was enough for subjects to make improvements in their production without explicit direction. Another study that has found textual enhancement is effective in drawing learners' attention to forms was conducted by Jourdenais, Ota, Stauffer, Boyson, and Doughty (1995). They attempted to identify whether typographical input enhancement makes target forms more noticeable and influences learners' on-line processing of L2 grammatical features. This study also showed that text enhancement has a positive effect on learners' production of the second language.

White (1998) investigated whether text enhancement promoted the acquisition of possessive determiners of English among a group of French-speaking children. The target forms were typographically enhanced through underlining, italic, bolding and text enlargement. The subjects were divided into three treatment groups. The first group was given passages with textual enhancement on the possessive determiners plus extensive reading and listening with the target forms; the second group was given the same passages with the enhanced passages only; and the third group was given the unenhanced version of the passages. The subjects were asked to answer some questions on possessive determiners related to the story on the assessment task. Results indicated that all three groups improved their ability to use the target forms in an oral communication task. The post-tests scores for the two groups that received enhanced forms were higher than the scores of subjects in the unenhanced group. The results for the delayed post-tests, which were given five weeks later, showed that the enhanced group had a better performance in using the target forms compared with the other groups. This suggests that subjects in the enhanced group benefited from enhanced input; however, the differences were not significant.

A second group of researchers have found that textual enhancement has a positive effect on learners' noticing the enhanced forms, but it is ineffective in helping learners acquire target language forms. Leow (1997), for example, examined the effects of typographical enhancement and text length on 84 Spanish students of native English speakers. The form chosen in this study was the impersonal imperative Spanish forms of which the subjects had limited knowledge prior to the study. The result showed that written input enhancement had no significant effect on learners' comprehension of the passage and that it did not draw the subjects' attention to the target forms successfully. In another study, Leow (2001) tried to find out whether using text enhancement would have a positive effect on learners' noticing the target forms, the formal imperative command in Spanish. There were 38 participants in the study who were divided to an experimental group and a control group. The subjects had not had any instruction on the target forms prior to the study. Assessment was in the form of a written production and a recognition task. Results showed that there was no significant difference between the enhanced and unenhanced groups in terms of noticing the target forms.

Alanen (1995) studied the effectiveness of textual enhancement with and without explicit rule instruction on grammatical morphemes in Finnish. He examined whether giving learners explicit rules about the target forms would make a difference in lexical acquisition. The results showed that the participants who read the texts with the italicized target forms used them more often than those who read the unenhanced texts. In this study, the findings suggested that textual enhancement positively influenced the subjects' noticing of the target forms, but it did not result in better production of the L2 forms. Alanen (1995) further stated that giving learners explicit rules of the target forms tended to be more effective than using textual enhancement alone. Furthermore, in Williams's 
(1999) study, sixteen participants were exposed to the texts with highlighted Italian pronouns and later they took a verbatim memory task and a translation task. The results displayed that the participants who read the enhanced texts performed better on the memory task than those who did not.

A more recent study that reports textual enhancement facilitates learners' noticing language features is Wong (2003). He attempted to find out the relative effectiveness of typographical enhancement and simplified input on adult French learners, learning the past participle agreement in relative clauses. The subjects were divided into four groups, which differed with respect to (+/-) textual enhancement and (+/-) simplified input. The subjects had no formal instruction on the target forms. They were asked to perform an error correction task in which they had to correct the errors in a text, and do a free recall task after reading the text. Results revealed that text enhancement did not have a positive impact on the knowledge and acquisition of the target forms, but it helped the learners notice the structure.

Kim (2003) investigated the relative effectiveness of typographical enhancement, lexical elaboration and a combination of both among a relatively large sample of Korean learners of English. Three types of texts were used in this study: (1) an explicitly lexically elaborated text with target words followed by a synonym or a definition type vocabulary explanation; (2) an implicitly lexically elaborated text with an appositive vocabulary explanation only; and (3) a typographically enhanced text with target words set in bold face to test the acquisition of 26 low-frequency words. The results showed that (a) lexical elaboration alone did not facilitate form recognition of L2 vocabulary; (b) explicit lexical elaboration alone led to more meaning recognition of L2 vocabulary; (c) typographical enhancement alone did not facilitate form and meaning recognition of L2 vocabulary; (d) lexical elaboration and typographical enhancement combined led to more meaning recognition of L2 vocabulary; (e) both explicit and implicit lexical elaboration facilitated meaning recognition of L2 vocabulary; (f) there was no significant difference between explicit and implicit lexical elaboration in terms of their effect on form and meaning recognition of L2 vocabulary.

In a more recent study, Cho (2010) investigated the effects of textual enhancement, in the form of underlining and bolding, on learners' noticing and on acquisition of the English present perfect tense. The results indicated that textual enhancement positively influenced the learners' noticing and acquisition of the target forms. Nevertheless, some studies have shown that text enhancement even negatively influences students' learning of a second language. For example, Overstreet (1998) identified the effect of text familiarity on the comprehension and production of the students. The subjects were students of Spanish in the third semester at the University of Illinois. All subjects had received some instruction on the difference between the preterit and imperfect forms before the study. Overstreet reported that there was no positive effect for either text enhancement or content familiarity on production and recognition. However, there was a negative effect on the subjects' comprehension of the passages. Overstreet concluded that the text enhancement had taken subjects' attention away from the overall comprehension.

It seems that the effectiveness of textual enhancement in SLA has not been constant in previous studies on the effects of visual input enhancement-both those that used short-term treatment with rather limited exposure to the input (Alanen, 1995; Jourdenais, Ota, Stauffer, Boyson, \& Doughty, 1995; Leow, 1997; Robinson, 1997; Shook, 1994; Williams, 1999) and those that used longer-term treatment with a greater amount of input exposure (Doughty, 1991; Jourdenais, 1998; White, 1998). One group of these studies (Doughty, 1991: Jourdenais, Ota, Stauffer, Boyson, \& Doughty, 1995; Shook, 1994; and Williams, 1999) yielded positive findings for the facilitative effect of the enhancement, whereas some of them (Alanen, 1995; Robinson, 1997; White, 1998) showed only limited effects and some others (Leow, 1997; Jourdenais, 1998) found no significant effect at all.

Though some of the above-mentioned studies suggested that input enhancement is effective in learning language features, the results are not consistent. It appears that simply increasing the salience of linguistic forms through typographical enhancement is not enough to make a difference in encouraging greater learning of language features. It might be that L2 learners need something more than mere enhancement of the input in order 
to foster their learning and retention of linguistic features. In line with this argument, more insights come from a group of studies that have suggested linguistic modifications of original texts can lead to better learning of linguistic features by L2 learners (Brown, 1985; Kim, 2003; Parker, \& Chaudron, 1987; Urano, 2000; Yano, Long, \& Ross, 1994).

\subsection{Input simplification and input elaboration}

Two major types of modifications have been used to make the incoming input more comprehensible or to adjust the input to learners' level of understanding: simplification and elaboration. Simplification refers to changes to the input so that there is less syntactical and lexical complexity, while elaboration refers to changes in which unfamiliar linguistic items are paraphrased with redundancy and explicitness (Le, 2011). The typical features of simplification include the addition of sentence connectors and boundary markers; repetitions of words and phrases; removal of subordinate clauses to reduce sentence length and complexity; and the restriction of lexis to familiar items. In simplified texts, specialist use replacement or omission to make complex text easier for the learners to understand (Yano, Long, \& Ross, 1994). In other words, they either replace an item by another which is considered to be simpler and thus easier to understand or omit an item or structure deemed complex and thus difficult to understand. One can argue that this may increase the comprehensibility of a text, but it removes low frequency items and structures which the learners need to acquire. As a an alternative to linguistic simplification, in elaborative modification much of the original complexity is maintained in the text, but compensating by clarifying the message content and structure and by adding redundancy and paraphrasing (e.g. through the use of repetition and paraphrasing). Where vocabulary is concerned, definitions and parenthetical explanations of difficult words are given.

Parker and Chaudron (1987) defined elaboration in a slightly different way from others. They suggested an operational definition for elaboration, i.e. "the addition of redundancy, and the explicit realization of underlying thematic relations" (p. 110). Elaboration is believed to facilitate language learning through paraphrases, synonyms and restatements; optional syntactic signals; rhetorical signaling devices; slowness of rate of speech, clearer pronunciation and emphatic stress; and self-repetition (Parker \& Chaudron, 1987, p. 110).

Several studies compared the effects of simplification and elaboration on L2 comprehension (Brown, 1985; Tsang, 1987; Yano, Long, \& Ross, 1994; and Chung, 1995). Brown (1985) tested the reading comprehension of 30 ESL students in Taiwan with three different versions of a text: the NS baseline version; the Modified Input version (i.e., simplified version) with modification in sentence structure and vocabulary; and the Modified Interactional Structure version (i.e., elaborated version), which retained the native speaker level of difficulty, but elaborated information through redundancy and repetition. The results of 20 multiple-choice questions after reading the text showed that scores of both simplified and elaborated conditions were significantly higher than that of the NS baseline condition. Although the elaborated group obtained a higher score than the simplified group, the difference was not statistically significant.

Tsang (1987) found similar results in a study on 401 ESL students in Hong Kong. Using the same texts as used by Brown (1985), she examined the differences in comprehension among the baseline, simplified, and elaborated texts with Cantonese-speaking students at five different grade levels. The results for the lowest two grades (i.e., Grades 9 and 10) displayed significantly higher scores for the simplified and elaborated groups compared with the baseline group.

The use of elaboration as substitute to simplification of original text has also received support from researchers, including Ross, Long, \& Yano (1991) and Yano, Long, \& Ross (1994). Yano, Long, \& Ross (1994) did not support the use of simplification since it deprives the L2 learner of an opportunity to learn new linguistic items. They prepared thirteen reading passages with three different forms (i.e., NS baseline, simplified, and elaborated) for their experiment with 483 Japanese college students. In the simplified texts, the length of sentences and number of the number of multisyllabic words and embedded clauses were kept to a minimum. 
Parenthetical paraphrase or definitions of low-frequency content words were used to create the elaborated version of the texts. The scores of 30 comprehension questions showed that the simplified version was significantly easier to comprehend than the baseline condition, but no statistically significant difference was found between the elaborated condition and the baseline condition. Yano, Long, and Ross (1994) further concluded that that elaboration performed better than both simplified and baseline versions in mean scores of "inference" questions.

Chung (1995) reviewed earlier studies on simplification and elaboration and came to the conclusion that both simplification and elaboration would facilitate L2 reading comprehension. She also investigated effects of two types of elaboration, i.e., lexical elaboration and structural elaboration. Chung (1995) prepared five different versions of a reading passage: unmodified baseline, simplified, lexically elaborated, structurally elaborated, and lexically \& structurally elaborated. In the simplified version, she rewrote compound sentences as several simple declarative sentences which expressed a single main idea per sentence, used the active voice where possible, and substituted low-frequency words with high-frequency ones. Lexical elaboration was achieved by adding definition, synonym, and hyponym, to the language items which were thought to be unknown to the participants. Similarly, structural elaboration was achieved by adding redundancy to the text in order to clarify message content and organization through signaling of intersentential relationships, retention of full NPs, supplying omitted elements, using anaphoric rather than cataphoric reference, and paraphrasing for summary statements which make already existing logical relations explicit without adding new information. The lexically and structurally elaborated text was generated by combining lexical and structural elaboration. Results of the 20-item multiple-choice comprehension test showed a significant difference between the baseline version and the simplified forms of the texts. No significant differences, however, were found between the elaborated conditions and the baseline condition.

Blau (1982) created three different versions of a text: Version one with short, simple sentences; Version two with complex sentences with clues to underlying relationships; and Version three made up of complex sentences without clues to underlying relationships. Scores on 24 multiple-choice comprehension questions by two groups, i.e., ESL university students and ESL 8th graders, showed no significant difference. The researcher argued that the use of simple sentences does not necessarily aid comprehension.

Parker and Chaudron (1987) created two different types of a passage for their study: an elaborated versions, which retained all the redundancy and thematic structure, and which was modified with some additional changes of the same type; and a non-elaborated version, which had all redundancies eliminated and all the thematic structure reduced to canonical word order form. Forty-three college students took part in the study, and answered a reading comprehension cloze test after reading one of two different types of passages. They found no statistically significant difference between the scores of the unmodified version and the elaborated version. Therefore, what Parker and Chaudron (1987) studied was not necessarily the effects of elaboration relative to the NS baseline text, but rather a comparison of elaboration with simplification.

Urano's (2000) study suggests that (a) both lexical simplification and elaboration facilitate L2 comprehension at the sentential level; (b) elaborating target lexical items can trigger acquisition of those elaborated words, whereas lexical simplification hinders acquisition of the target words; and (c) one occurrence of each target word with lexical elaboration may be insufficient for acquisition of its meaning, although more advanced learners may be able to learn some of the words on the basis of only one encounter. Also, Kim (2003) found that lexical elaboration helped meaning recognition among Korean learners of English.

The concept of input modification has recently received more attention among researchers in Iranian EFL context. Anani Sarab and Karimi (2012) studied the role of interactionally-modified input in text comprehension. A comparison was made in this study between linguistically-modified (LM) texts and interactionally-modified (IM) texts. The result of using texts under the two conditions and the control condition of using unmodified (U) texts showed that the learners' comprehension was highest under the interactionally-modified text condition and 
Birjandi, P., Alavi, S. M., \& Najafi Karimi, S.

lowest under the unmodified text condition with the linguistically-modified text condition in between.

Negari and Rouhi (2012) compared the effects of two types of lexical modification i.e., lexical simplification and elaboration, on incidental vocabulary acquisition of Iranian EFL learners. Four versions of experimental texts containing 20 target words were created: baseline and simplified versions, as well as

elaborated version with two types, i.e., parenthetical elaborated and non-parenthetical elaborated version. Results of two immediate surprise tests, i.e., form recognition test and meaning production test measuring incidental vocabulary learning from modified target words revealed that (a) lexical simplification did not result in incidental vocabulary acquisition (b) both parenthetical and non-parenthetical elaboration were conducive to incidental vocabulary acquisition and (c) comparatively, parenthetical elaborated group outperformed non-parenthetical elaborated group on two incidental vocabulary measures.

Also, Maleki and Pazhakh (2012) investigated the effects of pre-modified input, interactionally modified input and modified output on $80 \mathrm{EFL}$ learners' comprehension of new words. The subjects were randomly assigned into four groups of pre modified input, interactionally modified input, modified output and unmodified (control) groups. The participants in the experimental and control groups were taught under different conditions. In each session a matrix picture of a place and its furniture and equipment was given to the participants and they were trained to find the right position of each item. The findings of the study revealed that the participants in interactionally modified input group achieved the highest comprehension scores among their peers in other three groups. In addition, the modified output group outperformed both pre-modified input and control groups. However, the researchers did not find any significant difference between pre-modified input and control groups.

We can notice that in all above-mentioned studies the effects of elaboration are not so consistent. Some of the above-mentioned studies have dealt with the theoretical aspect of using elaborative modifications (Chaudron, 1982; Le, 2011; Long, 1983; Pica, Young \& Doughty, 1986). Many of these studies have been of the structural type, and very few of them have studied lexical elaboration. These studies have generally tested the effects of structural or lexical elaboration or a combination of the two on reading comprehension of L2 learners (Anani Sarab \& Karimi, 2012; Blau,1982; Negari \& Rouhi; Oh, 2001; Parker, \& Chaudron, 1987) or on listening comprehension (Toya, 1992). Some of them also investigated the role of lexical modification on vocabulary learning (Ellis, 1995; Kim, 2003; Maleki \& Pazhakh, 2012; Negari \& Rouhi, 2012; Silva, 2000). No study, however, has so far dealt with the elaboration of English phrasal verbs. It is of interest to the present research to find out whether using elaborative modification of phrasal verbs in a text will facilitate their acquisition among learners of English.

\subsection{Phrasal verb instruction}

A phrasal verb is a phrase which consists of a verb in combination with a preposition or adverb or both the meaning of which is different from the meaning of its separate parts such as 'look after', 'work out' and 'make up for' (Koprowski, 2005). According to Trask (1993; p: 208) a phrasal verb is a lexical verb "which consists of a simple verb combined with one or more particles" and whose meaning is typically unpredictable. In other words, phrasal verbs are two-or three-word idiomatic expressions, consisting of a verb and a particle or a combination of a particle and a preposition (Lewis, 1993).

Phrasal verbs have been the source of frustration for learners of English. Many students talk about the difficulties they have using the phrasal verbs. Phrasal verbs are widely used by native speakers of English but they have been found to be difficult for second language learners to master (Moon, 1997; Kao, 2001). The subject of how best to teach phrasal verbs is still quite controversial. As teaching of phrasal verbs has been difficult for teachers, and therefore confusing for learners, it is necessary to develop second language learners' skills in understanding and using them. Since phrasal verbs are frequently used by native speakers both in written and spoken English, students need to be encouraged to learn them. Even though the importance and the difficulty of learning phrasal verbs are recognized, there has been little research on testing the factors that 
Effects of unenhanced, enhanced, and elaborated input on learning English phrasal verbs

influence learning phrasal verbs so far (Liu, 2003; Nassaji \& Tian, 2010).

\section{The present study}

A review of the literature on the role of input reveals that there has always been a controversy over the effectiveness of providing learners with comprehensible input, input enhancement, input elaboration, and whether one or a combination of some is more beneficial in the process of learning language components (Izumi, 2002; Krashen, 1998; Maftoon \& Sharifi, 2012; White, 1998).

A number of studies have investigated the role of input enhancement on different areas of language, especially, grammar (Kuiken \& Vedder, 2002; Rott, 2007; Wong, 2012), structure (Abadikhah \& Shahriyarpour, 2012), writing (Storch, 1998, Van Gelderen, Snellings, \& De Glopper, 2004), and vocabulary (Izumi, 2002; Kim, 2008; Maftoon \& Sharifi, 2012; Silva, 2000). The role of input elaboration, however, has rarely been dealt with in promoting learners' knowledge of English (Kim, 2003), in general, and in teaching and learning English phrasal verbs, in particular. Even though the importance and the difficulty of learning phrasal verbs as a subcategory of vocabulary is recognized, there has been little research so far on testing the factors or conditions that influence learning and teaching phrasal verbs (Cornell, 1985; Liu, 2003; Nassaji \& Tian, 2010). Furthermore, to the best of the researchers' knowledge, there has been no study conducted in Iranian EFL context dealing with the effects of elaborated input on the acquisition of English phrasal verbs. The studies conducted in this context often included other aspects of input or other areas of language (Abadikhah \& Shahriyarpour, 2012; Khatib \& Ghannadi, 2011; Maftoon \& Sharifi, 2012; Maleki \& Pazhakh, 2012; Negari \& Rouhi, 2012).

The purpose of the present study was to examine and compare the relative effectiveness of unenhanced and enhanced input in contrast with elaborated input on the acquisition of phrasal verbs by Iranian EFL learners. The present study is also important in that it deals with the instruction of phrasal verbs, as a subgroup of English vocabulary, which is widely used by native speakers of English. Phrasal verbs have been found to be difficult for L2 learners to master as asserted by previous researchers (Hulstijn \& Marchena, 1989; Kao, 2001; Moon, 1997).

\subsection{Research questions}

The research questions were based on the consideration of the results of the prior theoretical and empirical research discussed above. Accordingly, the following research questions have been examined in this study.

1. Would the subjects receiving enhanced input demonstrate greater learning of the target phrasal verbs than the subjects receiving unenhanced input?

2. Would the subjects receiving elaborated input demonstrate greater learning of the target forms than the subjects receiving unenhanced input?

3. Would the subjects receiving elaborated input demonstrate greater learning of the target forms than the subjects receiving enhanced input?

\subsection{Participants}

This study is a quasi-experimental, time-series design study. It is quasi-experimental because the participants were not selected through true randomization. The original sample included three classes of sophomore students (a total of 115 students) majoring at English translation in an Iranian university (Islamic Azad university, Qaemshahr Branch). Since the study was conducted in the middle of a 15-week semester and took five sessions for the proficiency test, the pre-tests, and the three treatment sessions, it was not possible to select the participants through true randomization. Thus, one intact class (46 students) was randomly selected for the experiment. All of the participants have been studying English translation at the Islamic Azad University for two years. The participants from the intact class took part in a paper-based TOEFL proficiency test from Broukal (1997), Pearson Education Center, which was used to check the homogeneity of the group in terms of their 
proficiency level. Thirty five of the learners whose scores on the language proficiency test fell within \pm 1 standard deviation of the mean score were selected as participants for this study.

\subsection{Research design}

The study was conducted during a regular 15-week semester at the Azad University, Ghaemshahr Branch. The study was carried out in five sessions during a four-week period in the middle of the semester. After the proficiency test, the subjects participated in the treatment sessions which were held in four sessions. In the first session, the 30 target phrasal verbs were given to the subjects in the form of three ten-item, multiple-choice tests to answer. This was to test their prior knowledge of the target forms. Then, in the three following sessions, the subjects were exposed to the target forms in three different forms; unenhanced input (UI), enhanced input (EI) and elaborated input (ELI). The same tests were used as post-tests to check the knowledge gain of the participants.

In the first session of the treatment (unenhanced input), all participants were exposed to two types of texts: one short descriptive text and one short interview in which ten of the 30 target forms were used. The subjects were told that they had to read the texts in 15 minutes and later to write a summary of them. A glossary of the target forms was provided and handed out so that the learners might use it as a source of definitions for the unknown phrasal verbs. Then the researcher collected the texts and the glossary, but right before they wrote the summary, the researcher handed out the first post-test which included the first ten target forms to check their knowledge gain of them through exposure to unenhanced input. Since the purpose of the research was to check the subjects' implicit learning of the target forms, their attention was diverted to the summary they were to write after reading the texts. The post-test, however, was given before they wrote the summary as we thought that writing a summary as a form of output task would influence their knowledge of the target forms. The subjects were then allowed to write their summaries which were not included in the analyses. The same procedure was repeated in the second session of the treatment in which the subjects were exposed to the enhanced input. The target forms in the descriptive text and the interview were highlighted in bold print to help the participants notice them. After reading the enhanced input, the subjects were given the second post-test which included the ten target forms studied in the second session. In the third session, the subjects were given the elaborated version of the input in which redundancies and parenthetical explanations and definitions of the target phrasal verbs were included in the descriptive text and the interview. The learners in this phase, however, did not have any glossary of the target forms after reading the texts and before writing the summary, the participants answered the third post-test which included the ten target forms used in the elaborated input texts.

\subsection{Materials}

Target phrasal verbs - Phrasal verbs are two-word or three-word idiomatic expressions, consisting of a verb and a particle or a combination of a particle and a preposition (Lewis, 1993). The reason for focusing on phrasal verbs is that these verbs are a subgroup of English vocabulary that are widely used by native speakers of English but they have been found to be difficult for L2 learners to master (Hulstijn \& Marchena, 1989; Kao, 2001). The difficulty of learning phrasal verbs lies in the fact that they consist of different combinations of verbs and particles and often the meaning of the phrase is different from the meanings of its parts (Side, 1990). The target phrasal verbs have been derived from the book "English phrasal verbs in use" by McCarthy \& O’Dell (2004). After selecting the interviews and short descriptive texts for the treatment sessions, they were slightly modified so that each text included five of the target 30 phrasal verbs, ten of which were given to the participants in each version of the input.

Proficiency test, pretest, and posttests - Before the treatment session began, all the subjects took part in a paper-based TOEFL proficiency test from Broukal (1997), Pearson Education Center, which has been used to check the homogeneity of the group in terms of their proficiency level. Three ten-item, multiple-choice pretests which were designed by the researcher included the thirty target phrasal verbs used in the unenhanced, enhanced 
and elaborated versions of the input. The same tests were used as posttests to check the knowledge gain of the participants. Each posttest was given to the participants at the end of each treatment session to check the subjects' knowledge gain after each type of treatment. Reliability of the pretest and the three posttests has been estimated by means of internal consistency of responses to every item in each test.

The TOEFL proficiency test, which has extensively been used by ETS, was utilized as a criterion to estimate the validity of the pre-tests and post-tests developed by the researchers in this study. Furthermore, an internal-consistency method (Cronbach's Alpha) was used to calculate the reliability of the test. The reliability was estimated from the test scores in the pre-tests and the post-tests. The underlying reason was that there was little variability in the pre-tests and post-tests scores which might have decreased the reliability indices. The reliability measure for the pre-test and post-tests (0.76) was high enough to confirm the reliability of the test. According to Jafarpour (1992), reliability of 0.60 and above is acceptable for teacher-made tests.

Input enhanced texts - Input enhancement is a concept in second language acquisition, coined by Sharwood Smith (1993), which has commonly been used to signal methods that an instructor uses to make selected features of a second language more salient for learners in such a way as to facilitate acquisition. It includes explicit, more traditional techniques drawing the learner's attention more overtly to how the language system works by discussing particular aspects of grammar and usage. As suggested by Izumi (2002), the basic method of the enhancement is simply increasing the perceptual salience of the target form via bolding and providing marginal gloss. With a particular form chosen for the target, the enhancement embedded in the texts aimed to achieve the integration of attention to form and attention to meaning.

Input elaborated texts - Elaboration incorporates features of internationally modified input derived from NSs talk directed to NNs in the sense used by (Yano, Long, \& Ross, 1994) and Kim (2003). As text elaboration in general tend to be applied to a text as a whole including syntax and lexis, with a primary goal of enhancing L2 learners' overall comprehension, but textual enhancement only includes lexis, only lexical elaboration was used in this study. Various techniques were used to form the elaborated version of the input. Synonyms and dictionary definitions were given after the phrasal verbs in the form of appositives, or phrases beginning with "which means, I mean, in other words, which is to say, i.e., that is".

\section{Results and discussion}

In order to investigate how input enhancement and input elaboration influence the learning of English phrasal verbs; the data collected from the two performances of the participants were analyzed using related samples Friedman's two-way ANOVA for pretest and posttest. Descriptive statistics of the performances of the participants on the pretest are presented in Table 1. As it can be inferred from the table, there was no significant difference among the performances of the participants on the three ten-item pretests containing thirty target phrasal verbs in three sections, each of which corresponding to the target forms that were used in the three versions of the input: unenhanced, enhanced and elaborated. This shows that the subjects had similar performances on the three tests.

\section{Table 1}

Mean scores and SDs of the participants' performance on the pre-tests

\begin{tabular}{|c|c|c|c|c|c|}
\hline & $N$ & Mean & $S D$ & Min & Max \\
\hline Unenhanced & 35 & 3.40 & 7.40 & 0.00 & 6.00 \\
\hline Enhanced & 35 & 3.22 & 3.52 & 1.00 & 6.00 \\
\hline Elaborated & 35 & 3.25 & 4.66 & 1.00 & 6.00 \\
\hline
\end{tabular}

Also, related samples Friedman's two-way ANOVA was used to check if there was any significant difference on the participants' performances on the pre-tests (Table 2). As the p value (.991) is higher than 0.05, there was no significant difference in this regard. Results of related samples Friedman's two-way ANOVA of the participants' performances on the three post-test (Table 2) indicates that the p value (.001) is lower than the 
Birjandi, P., Alavi, S. M., \& Najafi Karimi, S.

critical value .016. Thus, we conclude that there was a significant difference in the scores of the participants on the three post-tests. Regarding the fact that the subjects had similar performances on the same tests (used as the pre-tests), one can argue that the difference on the scores on the post-tests is attributed to the three different treatments, namely unenhanced, enhanced and elaborated input.

Table 2

Results of related-samples Friedman's two-way ANOVA for the pre-tests

\begin{tabular}{lll}
\hline & Sig. & Decision \\
\hline Pre-test & 0.991 & retain the null hypothesis \\
Post-test & 0.001 & reject the null hypothesis \\
\hline
\end{tabular}

Descriptive statistics of the performances of the participants on the three posttests are sown in Table 3 . The figures in the table indicate that the participants had the highest scores on the elaborated version of the input, with the mean score of 6.17 , followed by enhanced input, with the mean score of 5.57 , and the lowest score on the unenhanced input, with the mean score of 4.77 .

Table 3

Mean scores and SDs of the participants' performance on the post-tests

\begin{tabular}{lccccc}
\hline & $N$ & Mean & $S D$ & Min & Max \\
\hline Unenhanced & 35 & 4.77 & 1.37 & 2.00 & 8.00 \\
Enhanced & 35 & 5.57 & 1.68 & 4.00 & 8.00 \\
Elaborated & 35 & 6.17 & 1.33 & 4.00 & 8.00 \\
\hline
\end{tabular}

Paired comparisons of the subjects' performances on unenhanced input, enhanced input and elaborated input are shown in Table 4. As we can understand from the figures, the participants mean score on the enhanced input (5.57) was higher than their mean score on the unenhanced input (4.77). This means that the subjects showed a greater learning of the target phrasal verbs after reading the enhanced texts as compared with reading the unenhanced texts. This probably confirms the above idea that learners tend to ignore phrasal verbs because the verb and the particle are already known to them and they do not notice that that the combination of the two can bear a different meaning. However, they generally notice the typographically enhanced forms and this noticing can lead to better learning of phrasal verbs. The results are in line with the previous studies which confirmed that various forms of typographical enhancement leads to better noticing the target forms and thus to better learning of them (Jourdenais, Ota, Stauffer, Boyson, \& Doughty,1995; Shook,1994; White,1998). The difference of performance on the enhanced and unenhanced input, however, was not statistically significant with reference to our $P$ value (0.16).

\section{Table 4}

Paired comparisons of performances on post-tests through related-samples Friedman's two-way ANOVA

\begin{tabular}{lcl}
\hline & Sig. & Decision \\
\hline Enhanced-unenhanced & 0.40 & retain the null hypothesis \\
Elaborated-unenhanced & 0.00 & reject the null hypothesis \\
Elaborated-enhanced & 0.29 & retain the null hypothesis \\
\hline
\end{tabular}

It can be understood from Table 3 that the subjects scored better after reading the elaborated input (mean = 6.17) as compared with the unenhanced input (mean $=4.77$ ). The elaborated input had also a better effect on learning the target phrasal verbs in comparison with the enhanced input (mean = 5.57). This suggests that the method of lexical elaboration used in the present study was effective in helping the participants to learn the target forms. Moreover, it indicates that providing lexical elaboration for phrasal verbs through parenthetical definitions and redundancies are more effective than giving a glossary of the enhanced forms. The findings are also consistent with some of the previous findings in the related literature as to the positive effects of elaboration in leading to greater noticing of the target forms and thus resulting in better learning of them. 
Results of the present research are in line with findings of Kim (2003), who found that L2 learners benefit more from explicit means of lexical elaboration than from implicit means of elaboration, though the explicit devices of lexical elaboration (adding "which means" immediately after every target word) led to an artificial form of text in his study. In the present study, we employed a combination of both implicit and explicit means of lexical elaboration. Ultimate care was given to ensure that the resulting texts after lexical elaboration sound natural and pleasant to read.

\section{Conclusions, implications and suggestions for further study}

The present study set out to investigate whether input enhancement or input elaboration can better facilitate learning English phrasal verbs by Iranian EFL learners. Three questions were posed above as to the relative effectiveness of unenhanced, enhanced and elaborated input on noticing and learning of phrasal verbs by L2 learners. Regarding the first question, "would the subjects receiving enhanced input demonstrate greater learning of the target phrasal verbs than the subjects receiving unenhanced input?", we have found that the participants' performance on the enhanced input was better than that on the unenhanced input. This shows that the typographical enhancement was effective in leading to better noticing and thus to better learning of the target forms. Concerning the second research question, "would the subjects receiving elaborated input demonstrate greater learning of the target forms than the subjects receiving unenhanced input?", it was found that the subjects had higher scores on the posttest after reading the elaborated input in comparison with reading the unenhanced input. This suggests that lexical elaboration can lead to more noticing and better learning of phrasal verbs. Furthermore, with reference to the third research question, "would the subjects receiving elaborated input demonstrate greater learning of the target forms than the subjects receiving enhanced input?", the results showed that the participants' performance on the elaborated input was better than that on the enhanced input, though not statistically significant. The higher mean score, however, suggests that lexical elaboration of phrasal verbs has the potentials to help 12 learners develop a better learning of English phrasal verbs.

Findings of the present study are significant in that very few studies of input enhancement and input elaboration have dealt with lexical elaboration (Kim, 2003) and no study so far has dealt with the effects of lexical elaboration on learning English phrasal verbs. As it has been asserted in the literature that learning phrasal verbs is especially difficult for 12 learners (Cornell, 1985; Side, 1990), findings of the present study might be inspiring both for second language learners and teachers, and for material designers.

Using lexical modifications of difficult words in books have recently become common in many newly published books. This procedure, however, has never been employed with regard to phrasal verbs and other idiomatic expressions. As many authors expressed the difficulty both in learning and in using these idiomatic expressions, findings of the present research may offer some new grounds for the application of lexical elaboration for these expressions. Furthermore, the avoidance of phrasal verbs has been the focus of research in some recent studies, which have shown that 12 learners tend to avoid using phrasal verbs for different reasons. One reason is said to be the complexity of phrasal verbs in terms of form and in terms of meaning. The results of the present paper seem to be promising for teachers in handling the problems of teaching phrasal verbs. They may also be useful for students in coping with difficulty and complexity of learning and remembering the forms and meanings of the phrasal verbs.

The present study has particularly dealt with the effects of lexical elaboration on the instruction of phrasal verbs. Further studies are required to investigate the potential role of elaborative modifications on retention of phrasal verbs over time. The findings seem to be inspiring for future studies on idiomatic expressions and other formulaic expressions, which have been investigated in some recent studies (Boers, Eyckmans, \& Stengers, 2007; Sun \& Wang, 2003; Wray, 2000). Moreover, this study dealt with effects of different forms of input on learning English phrasal verbs. More research is needed to explore the effects of output tasks on the instruction of phrasal verbs. Besides, a comparative study of the relative effectiveness of input tasks and output tasks can shed further light on the controversial issue of phrasal verb instruction. 


\section{References:}

Abadikhah, S., \& Shahriyarpour, A. (2012). The role of output, input enhancement and collaborative output in the acquisition of English passive forms. Journal of Language Teaching and Research, 3(4), 667-676. http://dx.doi.org/10.4304/jltr.3.4.667-676

Alanen, R. (1995). Input enhancement and rule presentation in second language acquisition. In R. Schmidt (Ed.), Attention and awareness in foreign language learning (pp. 259-302). Honolulu. University of Hawai Second Language Teaching \& Curriculum Center.

Anani Sarab, M. R., \& Karimi. M. (2008). The impact of simplified and interactionally modified input on reading comprehension of Iranian EFL learners. Human Sciences, 56, $29-42$.

Blau, E. (1982). The effects of syntax on readability for ESL students in Puerto Rico. TESOL Quarterly, 16, 517528. http://dx.doi.org/10.2307/3586469

Boers, F. Eyckmans, J. \& Stengers H. (2007). Presenting figurative idioms with a touch of etymology: More than mere mnemonics? Language Teaching Research 11(1), 43-62. http://dx.doi.org/10.1177/1362168806072460

Broukal, M. (1997). TOEFL grammar flash. New Jersey: Peterson's Princeton.

Brown, R. L. (1985). A comparison of the comprehensibility of modified and unmodified reading materials for ESL. University of Hawai, $i$ working papers in ESL,6, 49-79.

Chaudron, C. (1982). Vocabulary elaboration in teachers' speech to 12 learners. Studies in Second Language Acquisition, 4, 170- 180. http://dx.doi.org/10.1017/S027226310000440X

Cho, M. Y. (2010). The effects of input enhancement and written recall on noticing and acquisition. Innovation in Language Learning and Teaching, 4(1), 71-87. http://dx.doi.org/10.1080/17501220903388900

Chung, H. (1985). Effects of elaborative modification on second language reading comprehension and incidental vocabulary learning, Unpublished Master's thesis, University of Hawai'i at Manoa.

Combs, C. H. (2009). What cognitive processes are triggered by input enhancement? Working papers in TESOL \& Applied Linguistics [Special issue], 4.

Cornell, A. (1985). Realistic goals in teaching and learning phrasal verbs. International Review of Applied Linguistics, 23, 269-280. http://dx.doi.org/10.1515/iral.1985.23.1-4.269

Doughty, C. (1991). Second language instruction does make a difference: Evidence from an empirical study of relativization. Studies in Second Language Acquisition, 13, 431-496. http://dx.doi.org/10.1017/S0272263100010287

Doughty, C. (2001). Cognitive underpinnings of focus on form. In P. Robinson (Ed.), Cognition and second language instruction (pp. 206-257). New York: Cambridge University Press. http://dx.doi.org/10.1017/CBO9781139524780.010

Doughty, C., \& Williams, J. (1998). Pedagogical choices in focus on form. In C. Doughty \& J. Williams (Eds.), Focus on form in classroom second language acquisition (pp. 197-261). New York: Cambridge University Press.

Ellis, R. (1995). Modified oral input and the acquisition of word meanings. Applied Linguistics, 16(4), 409-441. http://dx.doi.org/10.1093/applin/16.4.409

Hare, A. (2010). Incidental phrasal verb acquisition through second language reading. MA Thesis, Concordia University, Montreal, Quebec, Canada.

Hulstijn, J. H., \& Marchena, E. (1989). Avoidance: grammatical or semantic causes. Studies in Second Language Acquisition, 11, 241-55. http://dx.doi.org/10.1017/S0272263100008123

Izumi, S. (2000). Promoting noticing and SLA: An empirical study of the effects of output and input enhancement on ESL relativization. Unpublished doctoral dissertation, Georgetown University, Washington DC.

Izumi, S. (2002). Output, input enhancement, and the noticing hypothesis: an experimental study on ESL relativization. Studies in Second Language Acquisition, 24(4), 451-577. http://dx.doi.org/10.1017/S0272263102004023

Jafarpour, A. (1992). A course in language testing. Tehran: Payame Noor University Press.

Jourdenais, R. (1998). The effects of textual enhancement on the acquisition of the Spanish preterit and imperfect. 
Effects of unenhanced, enhanced, and elaborated input on learning English phrasal verbs

Unpublished doctoral dissertation, Georgetown University, Washington DC.

Jourdenais, R., Ota, M., Stauffer, S., Boyson, B., \& Doughty, C. J. (1995). Does textual enhancement promote noticing? A think-aloud protocol analysis. In R. Schmidt (Ed.), Attention and awareness in foreign language learning (pp. 217-258). Honolulu: University of Hawai Second Language Teaching \& Curriculum Center.

Kao, R. (2001). Where have the prepositions gone? A study of English prepositional verbs and input enhancement in instructed SLA. International Review of Applied Linguistics in Language Teaching, 39, 195-215. http://dx.doi.org/10.1515/iral.2001.002

Keating, G. (2008). Task effectiveness and word learning in a second language: The involvement load hypothesis on trial. Language Teaching Research, 12(3), 365-386. http://dx.doi.org/10.1177/1362168808089922

Khatib, M., \& Ghannadi, M. (2011). Interventionist (explicit and implicit) versus non-interventionist (incidental) learning of phrasal verbs by Iranian EFL learners. Journal of Language Teaching and Research, 2(3), 537-546. http://dx.doi.org/10.4304/jltr.2.3.537-546

Kim, Y. (2003). Effects of input elaboration and enhancement on second language vocabulary acquisition through reading by Korean learners of English. Unpublished doctoral dissertation. University of Hawai'i at Manoa.

Kim, Y. (2008). The role of task-induced involvement and learner proficiency in L2 vocabulary acquisition. Language Learning, 58 (2), 285-325. http://dx.doi.org/10.1111/j.1467-9922.2008.00442.x

Koprowski, M. (2005). Investigating the usefulness of lexical phrases in contemporary course books. ELT Journal, 59(4), 322-332. http://dx.doi.org/10.1093/elt/cci061

Krashen, S. D. (1998). Comprehensible output? System, 26, 175-182. http://dx.doi.org/10.1016/S0346-251X(98)00002-5

Kuiken, F., \& Vedder, I. (2002). The effect of interaction in acquiring the grammar of a second language. International Journal of Educational Research, 37, 343-58. http://dx.doi.org/10.1016/S0883-0355(03)00009-0

Le, H. T. X. (2011). Pre-modified input in second language learning. Hawaii Pacific University TESOL Working Paper Series 9(1, 2), 27-31.

Lee, S. K. (2007). Effects of textual enhancement and topic familiarity on Korean EFL students' reading comprehension and learning of passive form. Language Learning, 57, 87-118. http://dx.doi.org/10.1111/j.1467-9922.2007.00400.x

Lee, S. K., \& Huang, H. T. (2008). Visual input enhancement and grammar learning. Studies in Second Language Acquisition, 30, 307-331. http://dx.doi.org/10.1017/S0272263108080479

Leeman, J., Arteagoitia, I., Fridman, B., \& Doughty, C. J. (1995). Integrating attention to form with meaning: focus on form in content-based Spanish instruction. In R. Schmidt (Ed.), Attention and awareness in foreign language learning (pp. 217-258). Honolulu: University of Hawai Second Language Teaching \& Curriculum Center.

Leow, R. (1997). The effects of input enhancement and text length on adult L2 readers' comprehension and intake in second language acquisition. Applied Language Learning, 8, 151-182.

Leow, R. (2001). Do learners notice enhanced forms while interacting with the L2? An online and offline study of the role of written input enhancement in L2 reading. Hispania, 74, 496-509. http://dx.doi.org/10.2307/3657810

Lewis, M. (1993). The lexical approach. Hove: Teacher Training Publications.

Liu, D. (2003). The most frequently used spoken American English idioms: a corpus analysis and its application. TESOL Quarterly, 37(4), 671-700. http://dx.doi.org/10.2307/3588217

Long, M. H. (1983). Linguistic and conversational adjustments to non-native speakers. Studies in Second Language Acquisition, 5, 177-193. http://dx.doi.org/10.1017/S0272263100004848

Maftoon, P., \& Sharifi Haratmeh, S. (2012). The relative effectiveness of input and output-oriented tasks with different involvement loads on the receptive and productive vocabulary knowledge of Iranian EFL learners. The Journal of Teaching Language Skills, 4(2), 27-52.

Maleki, Z. \& Pazhakh, A. R. (2012).The effects of pre modified input, interactionally modified input, and 
Birjandi, P., Alavi, S. M., \& Najafi Karimi, S.

modified output on EFL learners' comprehension of new vocabularies. International Journal of Higher Education, 1(1), 128-137. http://dx.doi.org/10.5430/ijhe.v1n1p128

McCarthy, M. \& O’Dell, F. (2007). English phrasal verbs in use. Cambridge. Cambridge University Press.

Moon, R. (1997). Vocabulary connections: Multi-word items in English. In M. McCarthy (Ed.), Vocabulary: Description, acquisition and pedagogy (pp. 40-63). Cambridge: Cambridge University Press.

Nassaji, H., \& Tian, J. (2010). Collaborative and individual output tasks and their effects on learning English phrasal verbs. Language Teaching Research, 14(4) 397-41. http://dx.doi.org/10.1177/1362168810375364

Oh, S. Y. (2001). Two types of input modification and EFL reading comprehension. TESOL Quarterly, 35, 69-96. http://dx.doi.org/10.2307/3587860

Overstreet, M. (1998). Text enhancement and content familiarity: The focus of learner attention. Spanish Applied Linguistics, 2, 229-258.

Pica, T, Young, R., \& Doughty, C. (1986). Making input comprehensible: Do interactional modifications help? International Review of Applied Linguistics, 72, 1-25.

Rassaei, E., \& Karbor, T. (2013). The effects of three types of attention drawing techniques on the acquisition of English collocations. International Journal of Research Studies in Language Learning, 2(2). http://dx.doi.org/10.5861/ijrsll.2012.117

Robinson, P. (1995). Attention, memory, and the "noticing" hypothesis. Language Learning, 45, $283-331$. http://dx.doi.org/10.1111/j.1467-1770.1995.tb00441.x

Robinson, P. (1997). Generalizability and automaticity of second language learning under implicit, incidental, enhanced, and instructed conditions. Studies in Second Language Acquisition, 19, 223-247. http://dx.doi.org/10.1017/S0272263197002052

Ross, S., Long, M. H., \& Yano, Y. (1991). Simplification or elaboration? The effects of two types of text modification on foreign language reading comprehension. University of Hawai' $i$ Working Papers in ESL, 10, 1-32.

Rott, S. (2007). The effect of frequency of input-enhancements on word learning and text comprehension. Language Learning, 57(2), 165-199. http://dx.doi.org/10.1111/j.1467-9922.2007.00406.x

Schmidt, R. (1990). The role of consciousness in second language learning. Applied Linguistics, 11,206-226. http://dx.doi.org/10.1093/applin/11.2.129

Schmidt, R. (1994). Deconstructing consciousness in search for useful definitions for applied linguistics. AILA Review, 11, 11-26.

Schmidt, R. (2001). Attention. In P. Robinson (Ed.), Cognition and second language instruction (pp.3-32). New York: Cambridge University Press. http://dx.doi.org/10.1017/CBO9781139524780.003

Sharwood Smith, M. (1981). Consciousness-raising and the second language learner. Applied Linguistics, 2, 159-168. http://dx.doi.org/10.1093/applin/2.2.159

Sharwood Smith, M. (1993). Input enhancement in instructed SLA: Theoretical bases. Studies in Second Language Acquisition, 15, 165-179. http://dx.doi.org/10.1017/S0272263100011943

Shook, D. J. (1994). FL/L2 reading, grammatical information, and the input-to-intake phenomenon. Applied Language Learning, 5, 57-93.

Side, R. (1990). Phrasal verbs: Sorting them out. ELT Journal 44, 144-152. http://dx.doi.org/10.1093/elt/44.2.144

Silva, A. D. (2000). Text elaboration and vocabulary learning. Unpublished Masteral thesis, University of Hawai'i at Manoa.

Sjoholm, K. (1995). The Influence of cross-linguistic, semantic, and input factors on the acquisition of English phrasal verbs: A comparison between Finnish and Swedish learners at an intermediate and advanced level. Esbo: Åbo Akademi University Press.

Storch, N. (1998). Comparing second language learners' attention to form across tasks. Language Awareness, 7(4), 176-191. http://dx.doi.org/10.1080/09658419808667108

Sun, Y. C., \& Wang, L. Y. (2003). Concordancers in the EFL classroom: Cognitive approaches and collocation difficulty. Computer Assisted Language Learning, 16, 83-94. 
Effects of unenhanced, enhanced, and elaborated input on learning English phrasal verbs

http://dx.doi.org/10.1076/call.16.1.83.15528

Swain, M. (1993). The output hypothesis: Just speaking and writing are not enough. The Canadian Modern Language Review, 50(2), 158-164.

Toya, M. (1992). Form and explanation in modification of listening input in L2 vocabulary learning. Unpublished master's thesis, University of Hawai'i at Manoa.

Trask, R. L. (1993). A Dictionary of grammatical terms in linguistics. London: Routhledge.

Tsang, W. K. (1987). Text modification in ESL reading comprehension, Unpublished Scholarly paper, University of Hawai'i at Manoa.

Urano, K. (2000). Lexical simplification and elaboration: Sentence comprehension and incidental vocabulary Learning, Unpublished Masteral thesis. University of Hawai'i at Manoa.

Van Gelderen, A., Snellings, P., \& De Glopper, K. (2004). The effect of enhanced lexical retrieval on second language writing: A classroom experiment. Applied Psycholinguistics, 25, 175-200.

VanPatten, B. (1990). Attending to content and form in the input: An experiment in consciousness. Studies in Second Language Acquisition, 12, 287-301. http://dx.doi.org/10.1017/S0272263100009177

White, J. (1998). Getting the learners' attention: A typographical input enhancement study. In C. Doughty \& J. Williams (Eds.), Focus on form in classroom second language acquisition (pp. 85-113). Cambridge: Cambridge University Press.

Williams, J. (1999). Learner-generated attention to form. Language Learning, 49, 583-625. http://dx.doi.org/10.1111/0023-8333.00103

Wong, W. (2003). Textual enhancement and simplified input effects on L2 comprehension and acquisition of non-meaningful grammatical form. Applied Language Learning, 13, 109-132.

Wong, W. (2005). Input enhancement: From theory and research to the classroom. Boston: McGraw-Hill.

Wong, W. (2012). Second language education: Does text enhancement have an effect on teaching and learning Chinese classifiers? Paper presented at The Asian Conference on Education, Monmouth University.

Wray, A. (2000). Formulaic sequences in second language teaching: Principle and practice. Applied linguistics, 21(4), 463-489. http://dx.doi.org/10.1093/applin/21.4.463

Yano, Y., Long, M., \& Ross, S. (1994). The effects of simplified and elaborated texts on foreign language reading comprehension. Language Learning, 44, 189- 219.

http://dx.doi.org/10.1111/j.1467-1770.1994.tb01100.x 
Birjandi, P., Alavi, S. M., \& Najafi Karimi, S. 